\title{
Role of Angiotensin II in Potassium-mediated Stimulation of Aldosterone Secretion in the Dog
}

\author{
J. Howard Pratt, Department of Medicine, Indiana University School of \\ Medicine; Veterans Administration Medical Center, Indianapolis, \\ Indiana 46223
}

A B S T R A C T Potassium is known to enhance the aldosterone-stimulating action of angiotensin II. Such a synergistic interaction of potassium with angiotensin II could represent an action by angiotensin II to potentiate potassium as a stimulus. To examine for this effect of angiotensin II on potassium, plasma aldosterone levels were measured before and after an infusion of potassium chloride ( $15 \mathrm{meq}$ i.v.) into dogs without and with prevention of angiotensin II formation by captopril, an angiotensin converting-enzyme inhibitor. In addition, responses to potassium were measured in a group of dogs receiving angiotensin II plus captopril. After potassium infusion, control dogs showed an increase of $7.7 \pm 1.9(\mathrm{SEM}) \mathrm{ng} / \mathrm{dl}(P<0.001)$ in the level of plasma aldosterone. In contrast, captopril-treated dogs showed no change in plasma aldosterone concentration in response to potassium. When angiotensin II was administered to captopril-treated dogs responsiveness to potassium administration was restored (plasma aldosterone concentration increased by $7.4 \pm 2.1$ $\mathrm{ng} / \mathrm{dl}, P<0.002)$. ACTH stimulated aldosterone secretion despite captopril treatment $(P<0.001)$, however, ACTH produced a greater increase in the plasma aldosterone concentration in controls than in captopriltreated animals. It is evident from these results that stimulation of aldosterone secretion by potassium is considerably enhanced by angiotensin II. There appears to exist an important interdependence of these stimuli in the regulation of aldosterone secretion.

\section{INTRODUCTION}

Potassium is a potent stimulus of aldosterone secretion. Supplementation of diets with potassium increases aldosterone secretion (1-5) as does infusion of potassium

This work was presented at the National Meeting of The American Federation for Clinical Research, Washington, DC, 8 May 1982.

Received for publication 21 December 1981 and in revised form 23 March 1982. into the adrenal artery of the dog (6) and of the sheep (7). Small increases in plasma potassium concentration produce immediate and significant increases in plasma aldosterone levels (8). In addition to apparent direct adrenal effects, potassium contributes to the control of aldosterone secretion by potentiating the actions of other stimulatory factors. Sodium depletion increases aldosterone secretion to a greater extent when subjects are potassium replete than when potassium deplete $(2,4,9)$. Both in vivo and in vitro, potassium augments stimulation by angiotensin II and by ACTH (10-12). To what extent, if any, this synergism of potassium with other stimuli represents enhancement of potassium's stimulatory capacity by the other stimuli is unknown.

The present study examined for a dependency of potassium as a stimulus on angiotensin II, the major regulator of aldosterone secretion (13). Potassium was infused intravenously into dogs and the aldosterone stimulatory response was measured under conditions where angiotensin II was present, and again during prevention of angiotensin II formation by treatment with captopril, an angiotensin converting-enzyme inhibitor. It was found that under these conditions angiotension II must be present for potassium to stimulate aldosterone secretion.

\section{METHODS}

Conditioned female dogs weighing 19-26 kg were maintained on an ad lib. intake of Iams Chunks (Iams Food Co., Lewisburg, $\mathrm{OH}$ ). For the purpose of suppressing ACTH secretion, all dogs studied were given dexamethasone phosphate $2 \mathrm{mg}$ the afternoon before and between 0700 and 0800 $\mathrm{h}$ on the morning of the study. With the dogs in a restraining canvas sling, indwelling catheters were placed in the external jugular vein to permit blood sampling and in leg veins to permit continuous infusion. Experiments were begun after an equilibration period of $60 \mathrm{~min}$.

Responses to administered potassium were compared between three different groups: (a) control, (b) captopriltreated, and $(c)$ captopril plus angiotensin II-treated. Captopril (E. R. Squibb and Sons, Inc., Princeton, NJ) was given 
as an initial 5-mg i.v. bolus injection, and then was infused at a rate of $20 \mu \mathrm{g} / \mathrm{kg}$ per min. Angiotensin II (Ciba-Geigy Corp., Summit, NJ) was infused at a rate of $5 \mathrm{ng} / \mathrm{kg}$ per min. These infusions were started $60 \mathrm{~min}$ before administration of potassium and were continued for the duration of the study period. Potassium chloride $(0.52 \mathrm{meq} / \mathrm{ml}$ of normal saline) was infused at a rate of $1 \mathrm{meq} / \mathrm{min}$ for $15 \mathrm{~min}$. Blood samples were drawn at $-60,-30,-15,-5$, and 0 min before potassium infusion, and $5,10,15,30,45$, and $60 \mathrm{~min}$ during and after potassium infusion. In four experiments, captopril and angiotensin II were infused simultaneously in the usual manner, but potassium administration was withheld.

In a separate series of experiments, ACTH responsiveness was examined by giving ACTH (cosyntropin, Organon, Inc., West Orange, NJ) $10 \mathrm{U}$ i.v. by injection to dexamethasone suppressed dogs without and with captopril treatment (as above). There were six dogs in each group; blood samples were obtained before and up to $60 \mathrm{~min}$ after ACTH administration for measurement of aldosterone concentration.

The plasma aldosterone concentration was measured by radioimmunoassay (14), plasma 11-hydroxycorticosteroids by the competitive protein binding method of Murphy (15), and plasma renin activity (PRA) ${ }^{1}$ by the method of Haber et al. (16). The plasma potassium concentration was measured using the ion selective electrode procedure of the Astra-8 by Beckman Instrument Co.

Statistical analysis of responses to treatment was carried out by one- and two-tailed repeated measures analysis of variance (17). When appropriate, the Student's $t$ test for nonpaired observations was used to assess for differences between group means.

\section{RESULTS}

Base-line values for plasma concentrations of sodium and potassium in experimental groups were not significantly different from controls (Table I). The basal plasma aldosterone concentration was lower in captopril-treated dogs, however, this value was significantly lower only in comparison to dogs treated with captopril and angiotensin II. In all groups plasma concentrations of 11-hydroxycorticosteroids were at or below the detection limit of the assay of $2.5 \mu \mathrm{g} / \mathrm{dl}$, and potassium administration was not associated with any increase above this level.

Effects of treatment of PRA (Fig. 1). Captopril treatment increased PRA in every case, indicating that captopril inhibited generation of angiotensin II (18). Infusion of angiotensin II (plus captopril) suppressed PRA in all dogs, and thus the infusion rate was sufficient to inhibit release of renin (19). Potassium administration had no effect on PRA in either control or experimental dogs.

Effects of infusion of $\mathrm{KCl}$. An infusion of $15 \mathrm{meq}$ potassium produced increases in plasma potassium concentrations of $1.9 \pm 0.4$ (SEM) in control dogs, $1.4 \pm 0.1$ in captopril-treated dogs, and $1.5 \pm 0.2 \mathrm{meq} /$

\footnotetext{
${ }^{1}$ Abbreviation used in this paper: PRA, plasma renin activity.
}

TABLE I

Base-line Plasma Concentrations of Sodium, Potassium, and Aldosterone in Control and Experimental Groups

\begin{tabular}{lccc}
\hline & Sodium & Potassium & Aldosterone \\
\hline & meq/liter & meq/liter & $n g /$ dl \\
Control $(n=6)$ & $145 \pm 1$ (SEM) & $3.7 \pm 0.1$ & $5.6 \pm 2.2$ \\
Captopril $(n=6)$ & $149 \pm 1$ & $3.6 \pm 0.1$ & $2.4 \pm 0.6 !$ \\
Captopril + A II $(n=6)$ & $148 \pm 1$ & $3.5 \pm 0.1$ & $9.4 \pm 1.8 !$ \\
\hline
\end{tabular}

- Values represent the means of samples drawn at $-30,-15,-5$, and $0 \mathrm{~min}$.

t Difference significant at $P<0.01$

liter in captopril plus angiotensin II-treated dogs (Fig. 2). For each group increases in potassium were significant at $P<0.001$. Although potassium infusion produced a greater increment in plasma potassium concentration in control dogs than in either group of captopril-treated dogs, this difference was not significant.

In response to potassium infusion (Fig. 2), plasma aldosterone concentration increased in control dogs by $7.7 \pm 1.9 \mathrm{ng} / \mathrm{dl}(P<0.001)$. In marked contrast, potassium produced no significant increase in plasma aldosterone level in dogs treated by continuous infusion of captopril. With simultaneous infusion of captopril and angiotensin II, potassium infusion produced an

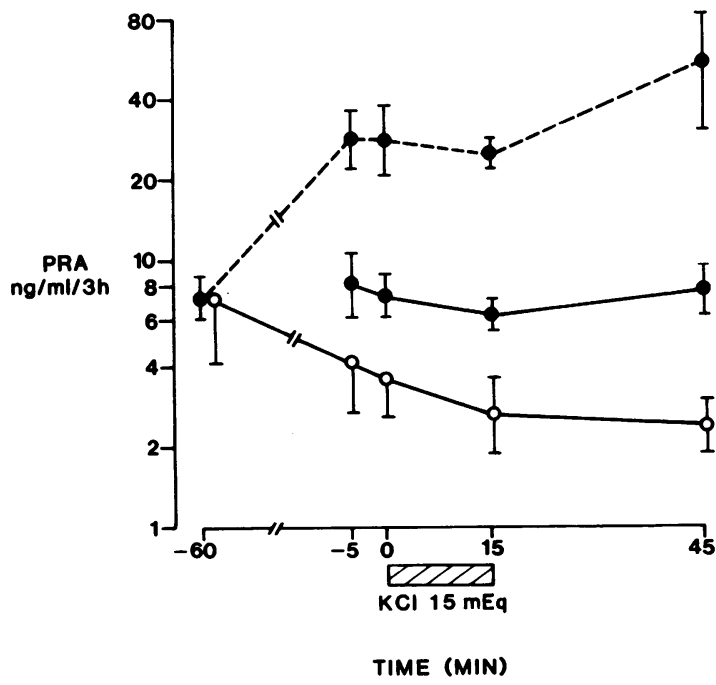

FIGURE l PRA in control dogs, $n=6(0)$; in captopriltreated dogs, $n=4(---\bullet)$; and captopril plus angiotensin II-treated dogs, $n=6(O)$. With the -60 min representing PRA at base line, in response to captopril infusion PRA increased, and during the simultaneous infusion of captopril and angiotensin II PRA decreased. Potassium administration was associated with no change in PRA in either control or experimental dogs. 


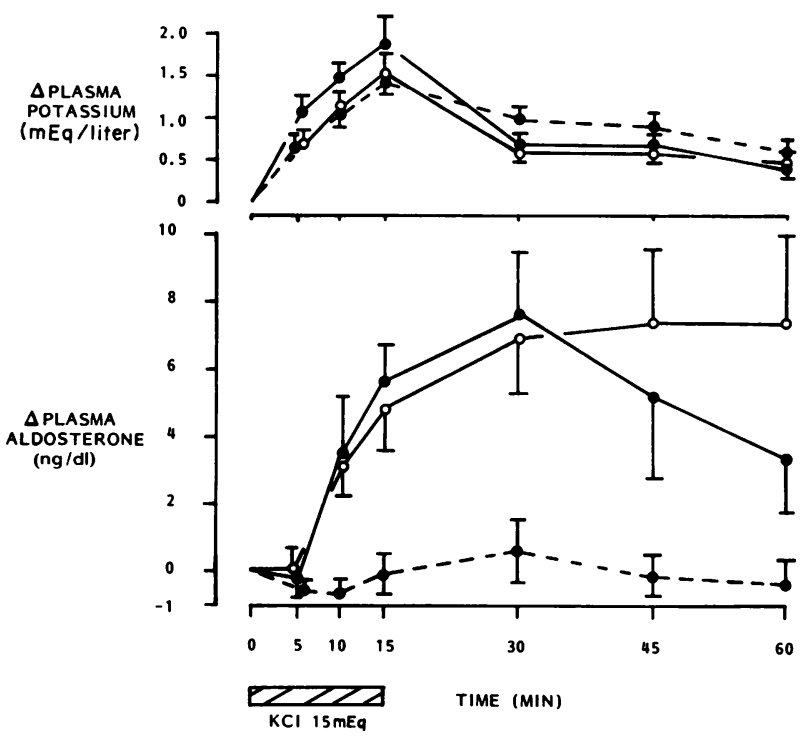

Figure 2 Changes in the plasma concentration of potassium and aldosterone in response to potassium chloride administered to control dogs, $n=6$ (0); captopril-treated dogs, $n$ $=6(---0)$; and captopril plus angiotensin II-treated dogs, $n=6(\mathrm{O})$. Plasma potassium concentration increased in all groups $(P<0.001)$ with no significant difference in responses between groups. Administered potassium produced an increase in plasma aldosterone concentration in control dogs $(P<0.001)$, but had no significant effect on the aldosterone level in captopril-treated dogs. When angiotensin II was given with captopril, the response to potassium was restored: the plasma aldosterone concentration increased to a level similar to that of control dogs, however, levels remained elevated in contrast to control dogs.

increase in plasma aldosterone concentration of $7.4 \pm 2.1$ $\mathrm{ng} / \mathrm{dl}(P<0.001)$ that was similar to that observed in control dogs.

The increase in plasma aldosterone concentration in angiotensin II plus captopril-treated dogs was sustained while the response in control dogs declined after $30 \mathrm{~min}$. The more prolonged response may have reflected stimulation by the infused angiotensin II. To examine for such an effect by angiotensin II, plasma aldosterone measurements were made over the same time period in a group of dogs receiving angiotensin II plus captopril, but no potassium. As shown in Table II, the plasma aldosterone level increased slightly with time despite the fact that potassium was not administered. However, a significantly greater increase in plasma aldosterone concentration occurred in dogs who also received potassium.

To better determine the threshold level of aldosterone secretory responsiveness to potassium, a lower dose of potassium, $10 \mathrm{meq}$, was infused over $15 \mathrm{~min}$ into control dogs (Fig. 3). Plasma levels of potassium increased by $0.9 \pm 0.1 \mathrm{meq} /$ liter, and aldosterone increased from $5.9 \pm 1.0$ to $10.3 \pm 1.9 \mathrm{ng} / \mathrm{dl}(P<0.02)$.

Effects of administered ACTH (Fig. 4). ACTH increased plasma aldosterone concentration in control and in captopril-treated dogs $(P<0.001)$. The magnitude of increase, however, was greater in the control group as compared to dogs receiving captopril ( $P$ $<0.05)$.

\section{DISCUSSION}

The present study demonstrates an essential role for angiotensin II in potassium-mediated stimulation of aldosterone secretion. Potassium had no effect on aldosterone secretion when generation of angiotensin II was inhibited by captopril. The addition of angiotensin II restored potassium's stimulatory action despite the simultaneous administration of captopril. In contrast to potassium, stimulation of aldosterone secretion by ACTH was reduced only slightly by captopril treatment. Since potassium is known to promote ACTH effects on aldosterone secretion (11) inhibition of potassium's actions by captopril may in turn have limited ACTH as a stimulus.

Potassium and angiotensin II have common features as stimuli of aldosterone production. They appear to have identical requirements for calcium (20-22), and both affect early and late steps in aldosterone biosynthesis (23). Neither potassium nor angiotensin II conveys its action by generation of cyclic AMP (24-27),

TABLE II

Changes in Plasma Aldosterone Concentration during Treatment with Captopril Plus Angiotensin II in Control and in $\mathrm{KCl}$-infused Dogs

\begin{tabular}{lcccccc}
\hline \multicolumn{1}{c}{ Time, $\min$} & 5 & 10 & 15 & 30 & 45 & 60 \\
\hline \multicolumn{7}{c}{ ng/dl } \\
Control $(n=4)$ & $-0.4 \pm 0.5$ & $-0.5 \pm 0.5$ & $1.1 \pm 0.5$ & $1.0 \pm 1.0$ & $2.2 \pm 0.9$ & $2.8 \pm 1$ \\
$\mathrm{KCl}(n=6)$ & $-0.1 \pm 0.6$ & $3.0 \pm 0.9 \ddagger$ & $4.9 \pm 1.2^{\circ}$ & $6.9 \pm 1.7^{\circ}$ & $7.4 \pm 2.1$ & $7.4 \pm 2.5$ \\
\hline
\end{tabular}

- $P<0.05$ from control.

$\downarrow P<0.02$ from control. 


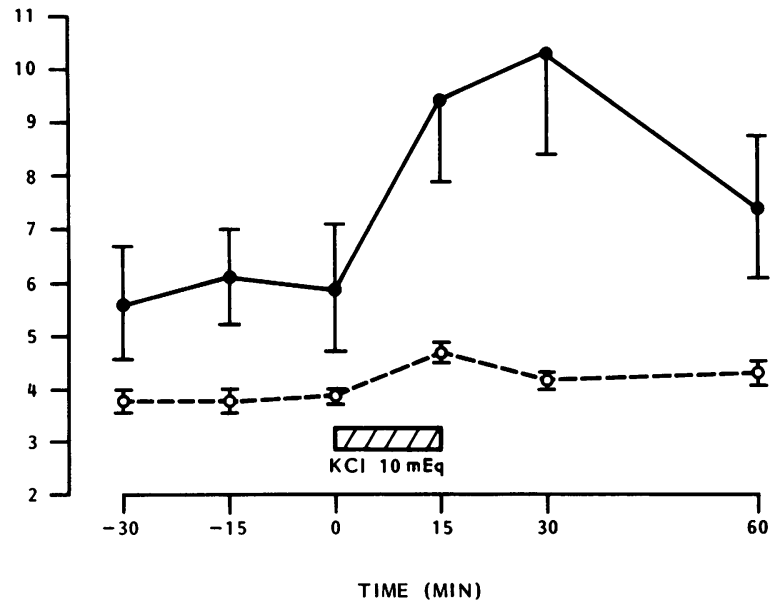

Figure 3 Effect of potassium chloride 10 meq on the plasma concentration of potassium (milliequivalents per liter, O-- - O) and aldosterone (nanograms per deciliter, - ) , $n=6$. This lesser dose of potassium chloride, 10 as compared with $15 \mathrm{meq}$ in the aforementioned studies, produced significant increases in plasma potassium concentration $(P<0.01)$ and plasma aldosterone concentration $(P$ $<0.02)$.

in contrast to other stimuli of steroidogenesis such as ACTH and LH $(28,29)$. These similarities in stimulatory actions suggest that potassium and angiotensin II act in tandem to affect aldosterone secretion. It has been suggested that potassium's sole influence is to modulate the stimulatory potential of angiotensin II (12). Present findings support such a concept since potassium had no stimulatory effect in the absence of angiotensin II. Furthermore, these results suggest that the well known synergism of potassium with angiotensin II to affect steroido-genesis may represent as much an angiotensin II potentiation of potassium as the reverse.

There is much previous evidence to show that potassium stimulates aldosterone production in the absence of angiotensin II. In vitro and without angiotensin II to affect steroidogenesis may represent as shown repeatedly by many investigators to stimulate production of aldosterone $(23,24,30,31)$, albeit, the addition of angiotensin II substantially enhances stimulation by potassium (12). This would appear to rule out an absolute requisite for angiotensin II by potassium. One might speculate, however, that exposure to angiotensin II in vivo, before death of the animal, might induce glomerulosa cells responsive to stimulation by potassium. In anephric patients, where angiotensin II levels are virtually absent, plasma aldosterone levels have been shown to correlate with the plasma potassium concentration (32), again suggesting that potassium acting alone or without angiotensin II can influence aldosterone production. However, it should be noted that in the anephric patient plasma aldosterone levels are extremely low (33), indicating that potassium appears to have little overall effect on aldosterone production.

The increment in potassium concentration during potassium infusion was less in captopril-treated dogs than in controls $(1.4 \pm 0.1$ vs. $1.9 \pm 0.1 \mathrm{meq} /$ liter $)$; a difference that was not, however, significant. Captopril, through its effect on eliminating angiotensin II formation, may have retarded the expected rise in plasma potassium concentration after potassium infusion. This is consistent with the demonstration by Healy et al. (34) that angiotensin II administered to the rabbit and to humans causes plasma potassium levels to increase. An effect of captopril to curtail potassium as a stimulus by preventing potassium levels to increase sufficiently was considered in the present study. It was determined in an additional group of control dogs that an infusion of 10 instead of 15 meq potassium stimulated aldosterone production despite a rise in plasma potassium concentration of $<1 \mathrm{meq} / \mathrm{liter}$. From this it would appear that captopril did not inhibit responsiveness to potassium by affecting plasma levels of potassium.

The intracellular potassium concentration of glomerulosa cells appears in some studies $(30,35,36)$, although not all $(37,38)$, to be important for normal responsiveness to stimuli of aldosterone secretion. One could hypothesize that for potassium to stimulate aldosterone secretion, intracellular potassium concentration must increase. An action of angiotensin II to permit potassium to enter glomerulosa cells and thereby

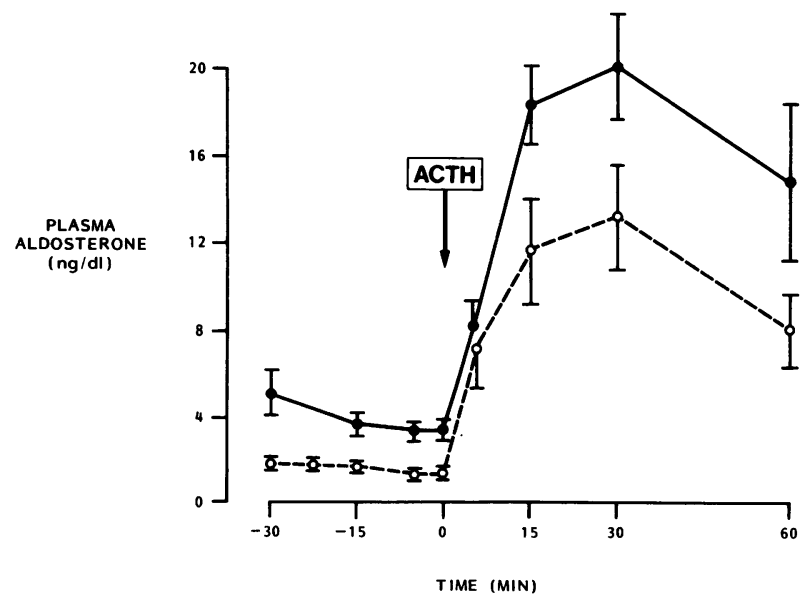

Figure 4 Plasma aldosterone concentration before and after administration of ACTH $10 \mathrm{U}$ i.v. in control dogs, $n$ $=6(-)$; and in captopril-treated dogs, $n=6(---)$. ACTH stimulated aldosterone secretion in both groups $(P$ $<0.001$ ), however, responsiveness to ACTH was less in captopril-treated than control dogs $(P<0.05)$. 
increase intracellular potassium concentration could explain the observed permissive action of angiotensin II. In this regard, Baumber et al. (39) showed in the dog that angiotensin II as well as other stimuli of aldosterone secretion caused adrenal cortical potassium content to increase. However, Szalay (40) showed that angiotensin II reduced intracellular potassium concentration of rat glomerulosa cells. Also, angiotensin II was found to have no effect on monovalent cation transport in adrenal glomerulosa tissue from the dog (36). Thus, most evidence would indicate that angiotensin II does not promote potassium as a stimulus by affecting entry of potassium into glomerulosa cells, and thus such a mechanism would not explain findings in the present study.

The present observations, although derived from studies carried out acutely, may have relevance to certain chronic states of angiotensin II deficiency. In hyporeninemic-hypoaldosteronism, the subnormal rate of aldosterone secretion is considered to result from impaired secretion of renin resulting in low levels of angiotensin II (41). Hyperkalemia ensues from the hypoaldosteronism and there is little or no apparent effect of the high potassium concentration to restore aldosterone secretion to normal. A similar situation of high potassium levels and low aldosterone production frequently exists in the anephric patient (42), although, as has been mentioned, the plasma aldosterone concentration tends to correlate proportionately with the concentration of potassium (32). Findings in the present study would suggest that the insensitivity to potassium in hyporeninemic-hypoaldosteronism patients and in anephric patients may well result from a deficiency of angiotensin II.

Patients with primary aldosteronism characteristically have suppression of the renin-angiotensin system (43). These patients would also be expected to show unresponsiveness to potassium should angiotensin II be required for potassium to stimulate aldosterone secretion. An absolute inability of potassium to stimulate in such patients was discounted in studies by Cannon et al. (2) who showed that an increase in dietary potassium produced an increase in aldosterone production in three patients. However, Ganguly et al. (44) showed in seven patients with primary aldosteronism that infusion of potassium, which raised the plasma potassium concentration by 0.4 to $0.6 \mathrm{meq} / \mathrm{liter}$, failed to increase plasma aldosterone levels, whereas in normal subjects these increments in potassium would result in an increase in aldosterone levels. Thus, in primary aldosteronism where there are low amounts of angiotensin II in plasma there may be considerably less sensitivity to potassium.

In summary, evidence is presented for an appreciable dependence of potassium on angiotensin II in the regulation of aldosterone secretion. Much remains to be learned as to how steroidogenesis is affected by these stimuli, but it would appear that potassium and angiotensin II may be more critically interdependent than previously recognized.

\section{ACKNOWLEDGMENTS}

The author is grateful for the excellent technical assistance of Ann C. Garner, Charles A. Parkinson, and Shirley L. Chastain. Plasma renin measurements were carried out by Mrs. Ann Haddix and statistical analyses were performed by Dr. Naomi S. Fineberg. Captopril was supplied by E. R. Squibb and Sons, Inc. Mrs. Sandi Wilson and Ms. Toni D. Moore were responsible for final preparation of the manuscript.

These studies were supported by the U. S. Veterans Administration Hospital and by U. S. Public Health Service grants HL-14159; HL-27294.

\section{REFERENCES}

1. Gann, D. S., C. S. Delea, J. R. Gill, Jr., J. P. Thomas, and F. C. Bartter. 1964. Control of aldosterone secretion by change of body potassium in normal man. Am. J. Physiol. 207: 104-108.

2. Cannon, P. J., R. P. Ames, and J. H. Laragh. 1966. Relation between potassium balance and aldosterone secretion in normal subjects and in patients with hypertensive or renal tubular disease. J. Clin. Invest. 45: 865879.

3. Dluhy, R. G., L. Axelrod, R. H. Underwood, and G. H. Williams. 1972. Studies in the control of plasma aldosterone concentration in normal man. II. Effect of dietary potassium and acute potassium infusion. J. Clin. Invest. 51: 1950-1957.

4. Boyd, J. E., W. P. Palmore, and P. J. Mulrow. 1971. Role of potassium in the control of aldosterone secretion in the rat. Endocrinology. 88: 556-565.

5. Baumann, K., and J. Muller. 1972. Effect of potassium intake on aldosterone biosynthesis in the rat. Acta Endocrinol. 69: 701-717.

6. Davis, J. O., J. Urquhart, and J. T. Higgins, Jr. 1963. The effects of alterations of plasma sodium and potassium concentration on aldosterone secretion. J. Clin. Invest. 42: 597-609.

7. Blair-West, J. R., J. P. Coghlan, D. A. Denton, J. R. Goding, J. A. Munro, R. E. Peterson, and M. Wintour. 1962. Humoral stimulation of adrenal cortical secretion. J. Clin. Invest. 41: 1606-1627.

8. Himathongkam, T., R. G. Dluhy, and G. H. Williams. 1975. Potassium-aldosterone-renin interrelationships. $J$. Clin. Endocrinol. Metab. 41: 153-159.

9. Johnson, B. B., A. H. Lieberman, and P. J. Mulrow. 1957. Aldosterone excretion in normal subjects depleted of sodium and potassium. J. Clin. Invest. 36: 757-766.

10. Hollenberg, N. K., G. H. Williams, B. Burger, and I. Hooshmand. 1975. The influence of potassium on the renal vasculature and the adrenal gland, and their responsiveness to angiotensin II in normal man. Clin. Sci. Mol. Med. 49: 527-534.

11. Williams, G. H., R. G. Dluhy, and R. H. Underwood. 1970. The relationship of dietary potassium intake to the aldosterone stimulating properties of ACTH. Clin. Sci. (Lond.). 39: 489-496.

12. Fredlund, P., S. Saltman, T. Kondo, J. Douglas, and 
K. J. Catt. 1977. Aldosterone production by isolated glomerulosa cells: modulation of sensitivity to angiotensin II and ACTH by extracellular potassium concentration. Endocrinology. 100: 481-486.

13. Davis, J. O. 1975. Regulation of aldosterone secretion. Handb. Physiol. 6: (Section 7: Endocrinology) 77-106.

14. Antunes, J. R., S. L. Dale, and J. C. Melby. 1976. Simplified radioimmunoassay for aldosterone using antisera to aldosterone-gamma-lactone. Steroids. 28: 621-630.

15. Murphy, B. E. P. 1969. Some studies of the protein binding of steroids and their application to the routine micro and ultramicro measurement of various steroids in body fluids by competitive protein-binding radioassay. $J$. Clin. Endocrinol. Metab. 27: 973-990.

16. Haber, E., T. Koerner, L. B. Page, B. Kilman, and A. Purnode. 1969. Application of a radioimmunoassay for angiotensin I to the physiologic measurements of plasma renin activity in normal human subjects. J. Clin. Endocrinol. Metab. 29: 1349-1355.

17. Nie, N. H., C. H. Hall, J. G. Jenkins, K. Steinberlnner, and D. H. Brent. 1970. Statistical Package for The Social Sciences. McGraw-Hill Book Co., New York.

18. Gavras, H., H. R. Brunner, G. A. Turini, G. R. Kershaw, C. P. Tift, S. Cuttelod, I. Gavras, R. A. Vukovich, and D. N. McKinstry. 1978. Antihypertensive effect of the oral angiotensin converting-enzyme inhibitor SQ 14225 in man. N. Engl. J. Med. 298: 991-995.

19. Vandongen, R., W. S. Peart, and G. W. Boyd. 1974. Effect of angiotensin II and its nonpressor derivatives on renin secretion. Am. J. Physiol. 226: 277-282.

20. Fakunding, J. D., R. Chow, and K. J. Catt. 1979. The role of calcium in the stimulation of aldosterone production by adrenocorticotropin, angiotensin II, and potassium in isolated glomerulosa cells. Endocrinology. 105: 327-333.

21. Fakunding, J. L., and K. J. Catt. 1980. Dependence of aldosterone stimulation in adrenal glomerulosa cells on calcium uptake: effects of lanthanum and veraparmil. Endocrinology. 107: 1345-1353.

22. Foster, R., M. V. Lobo, H. Rasmussen, and E. T. Marusic. 1981. Calcium: its role in the mechanism of action of angiotensin II and potassium in aldosterone production Endocrinology. 109: 2196-2201.

23. Aguilera, G., and K. G. Catt. 1979. Loci of action of regulators of aldosterone biosynthesis in isolated glomerulosa cells. Endocrinology. 104: 1046-1952.

24. Saruta, T., R. Cook, and N. M. Kaplan. 1972. Adrenocortical steroidogenesis: studies on the mechanism of action of angiotensin and electrolytes. J. Clin. Invest. 51: 2239-2245.

25. Peytremann, A., R. D. Brown, W. E. Nicholson, D. P Island, G. W. Liddle, and J. G. Hardman. 1974. Regulation of aldosterone synthesis. Steroids. 24: 451-462.

26. Espiner, E. A., J. H. Liversley, J. Ross, and R. A. Donald. 1974. Dynamics of cyclic adenosine 3,5-monophosphate release during adrenocortical stimulation in vivo. Endocrinology. 95: 838-846.

27. Shima, S., Y. Kawashima, and M. Harai. 1978. Studies on cyclic nucleotides in the adrenal gland. VIII. Effects of angiotensin on adenosine 3,5-monophosphate and steroidogenesis in the adrenal cortex. Endocrinology. 103: 1361-1367.

28. Haynes, R. C. Jr., and L. Berthet. 1957. Studies on the mechanism of action of the adrenocorticotropic hormone. J. Biol. Chem. 225: 115-124.

29. Marsh, J. M., R. W. Butcher, K. Savard, and E. W. Sutherland. 1966. The stimulatory effect of leuteinizing hormone on adenosine 3,5-monophosphate accumulations in corpus luteum slices. J. Biol. Chem. 241: 5436-5440.

30. Boyd, J., P. J. Mulrow, W. P. Palmore, and P. Silva. 1973. Importance of potassium in the regulation of aldosterone production. Circ. Res. 32, 33(Suppl. I): 1-39, 1-49.

31. Fredlund, P., S. Saltman, and K. J. Catt. 1975. Aldosterone production by isolated adrenal glomerulosa cells: stimulation by physiological concentrations of angiotensin II. Endocrinology. 97: 1577-1586.

32. Cooke, C. R., J. S. Horvath, M. A. Moore, T. Bledsoe, and W. G. Walker. 1973. Modulation of plasma aldosterone concentration by plasma potassium in anephric man in the absence of a change in potassium balance. J. Clin. Invest. 52: 3028-3032.

33. Sealey, J. E., R. P. White, J. H. Laragh, D. B. Case, and A. L. Rubin. 1978. Studies of plasma aldosterone in anephric people: evidence of the fundamental role of the renin system in maintaining aldosterone secretion. J. Clin. Endocrinol. Metab. 47: 52-60.

34. Healy, J. K., A. J. Elliott, and L. C. Harrison. 1974. Effects of angiotensin on plasma electrolyte concentrations in rabbits and in man. Clin. Sci. Mol. Med. 46: 1936 .

35. Braley, L. M., and G. H. Williams. 1978. The effects of ouabain on steroid production by rat adrenal cells stimulated by angiotensin II, alph 1-24 adrenocorticotropin, and potassium. Endocrinology. 103: 1997-2005.

36. Foster, R., M. V. Lobo, and E. T. Marusic. 1979. Studies of relationship between angiotensin II and potassium ions on aldosterone release. Am. J. Physiol. 237: E363E366.

37. Mendelsohn, F. A., and C. Mackie. 1975. Relation of intracellular $\mathrm{K}^{+}$and steroidogenesis in isolated adrenal zona glomerulosa and fasiculata cells. Clin. Sci. Mol. Med. 49: 13-26.

38. Lobo, M. V., E. T. Marusic, and G. Aguilera. 1978. Further studies on the relationship between potassium and sodium levels and adrenocortical activity. Endocrinology. 102: 1061-1068.

39. Baumber, J. S., J. O. Davis, J. A. Johnson, and R. T. Witty. 1971. Increased adrenocortical potassium in association with increased biosynthesis of aldosterone. Am. J. Physiol. 220: 1094-1099.

40. Szalay, K. S. 1969. Inhibiting effect of angiotensin on potassium accumulation of adrenal cortex. Biochem. Pharmacol. 18: 962-964.

41. Schambelan, M., J. R. Stockigt, and E. G. Biglieri. 1972. Isolated hypoaldosteronism in adults. A renin deficiency syndrome. N. Engl. J. Med. 287: 573-578.

42. Pratt, J. H., C. A. Parkinson, and F. C. Luft. 1978. A new approach to the difficult assessment of aldosterone secretion in anephric patients. Steroids. 32: 487-498.

43. Conn, J. W. 1964. Plasma renin activity in primary aldosteronism. JAMA (J. Am. Med. Assoc.) 190: 222-225.

44. Ganguly, A., M. Chavarri, and J. A. Luetscher. 1976. Control of plasma aldosterone in aldosterone-producing adenoma. Program of the $\mathrm{V}$ International Congress of Endocrinology, Hamburg, Federal Republic of Germany. 207 (Abstr.). 